\title{
National trends of pre-hypertension and hypertension among Iranian adolescents across urban and rural areas (2007-2011)
}

\author{
Parisa Amiri ${ }^{1}$, Golnaz Vahedi-Notash ${ }^{1}$, Parisa Naseri ${ }^{2,1}$, Davood Khalili ${ }^{3}$, Seyed Saeed Hashemi Nazari ${ }^{4}$, \\ Yadollah Mehrabi ${ }^{5}$, Ali Reza Mahdavi Hazaveh ${ }^{6}$, Fereidoun Azizi ${ }^{7}$ and Farzad Hadaegh ${ }^{3^{*}}$
}

\begin{abstract}
Background: The current nationwide study, for the first time, aimed to assess and compare the trend of prehypertension and hypertension among urban and rural adolescents in Iran.

Methods: This study has been conducted in the framework of the National Surveys of Risk Factors for NonCommunicable Diseases. To estimate pre-hypertension and hypertension prevalence among 9715 adolescents, aged 15-19years, data collected in four repeated cross-sectional surveys (2007-2011) has been used. The prevalence trends of pre-hypertension and hypertension were examined across urban and rural areas of Iran. To calculate the adjusted prevalence ratios (PRs) of pre-hypertension and hypertension over cycles across area of residence and genders, a complex sample survey and multinomial logistic analysis were performed.

Results: Using the definition of pre-hypertension and hypertension presented by the seventh Joint National Committee (JNC-VII) for adolescents, after adjusting for confounders, the prevalence of pre-hypertension changed in both urban (boys:28.96\% to $29.24 \%$ and girls:18.33\% to 20.06\%) and rural (boys 31.58\% to 32.05\% and girls $22.25 \%$ to $24.13 \%$ ) areas over the study duration. Non-significant rising prevalence of hypertension was also observed in boys and girls of both regions (urban $12.76 \%$ to $15.04 \%$ and $8.02 \%$ to $9.06 \%$; rural 9. $95 \%$ to $11.79 \%$ and $10.35 \%$ to $11.60 \%$, for boys and girls respectively). The adjusted prevalence ratios (PRs) of pre-hypertension $(2.16 ; 95 \% \mathrm{Cl} 1.68-2.79$ and $1.92,95 \% \mathrm{Cl} 1.57-2.34$, in urban and rural, respectively) and hypertension $(2.40 ; 95 \% \mathrm{Cl} 1.65-3.51$ and 1.82 , 95\% Cl 1.36-2.45, in urban and rural, respectively) were higher in boys than girls. Comparing the adjusted PRs of pre-hypertension and hypertension in urban versus rural areas, in both genders, showed higher PRs of pre-hypertension in rural girls $(1.33,95 \% \mathrm{Cl} 1.01-1.75)$.
\end{abstract}

Conclusion: The current results showed high constant trends of pre-hypertension and hypertension in Iranian boys and girls, residing in both urban and rural areas.

Keywords: Hypertension, Pre-hypertension, Adolescents, Urban, Rural

\section{Background}

Hypertension plays a pivotal role in predisposing adult population to cardiovascular diseases (CVDs), in the Middle East and North Africa (MENA)) regions [1, 2]. Accordingly, a recent WHO report indicates a considerable prevalence of hypertension in the Eastern

\footnotetext{
* Correspondence: fzhadaegh@endocrine.ac.ir

${ }^{3}$ Prevention of Metabolic Disorders Research Center, Research Institute for Endocrine Sciences, Shahid Beheshti University of Medical Sciences, Tehran, Iran

Full list of author information is available at the end of the article
}

Mediterranean region (EMR), ranging from $14.7 \%$ to $26.4 \%$ in different countries of this region [3]. Findings of a large national survey showed that $42.7 \%$ of Iranian adults suffer from high blood pressure including pre-hypertension and hypertension, according to the seventh report of the Joint National Committee on Prevention, Detection, Evaluation, and Treatment of High Blood Pressure (JNC-VII) [4]. It is well documented that hypertension beginning in childhood and adolescence is a predictor of high blood pressure in adulthood, contributing to early development of CVD disorders [5]. 
Although the latest pooled prevalence of hypertension among Iranian children and adolescents was estimated to be $8.9 \%$, slightly higher in boys than girls $(10.3 \%$ vs $9.1 \%$ ), and has a wide range (4.2 to $24.2 \%$ ) in different ages and residential areas of Iran [6, 7]. Hypertension is reported to be the most common comorbidity of overweight/obesity, showing an increasing trend in Iranian children as a probable consequence of their lifestyle changes through recent decades $[8,9]$.

Urbanization, a process through which changes in industries and economy cause expansion of cities and alter the way populations live, can significantly affect many aspects of a population's lifestyle, which could predispose them to CVD risk factors, including hypertension [10-12]. Existing data show the significant influence of urbanization and its consequences on the patterns of childhood physical activity, sedentary behaviors, and diet, in both developed and developing countries [13, 14]. While a number of studies revealed unhealthy lifestyles as being more prevalent among urban children [15], further evidence indicated some sort of homogeneity between urban and rural lifestyles through recent decades [14]; which can be attributed to the fast rising trend of modernization in particular development of amenities and greater access to communication technologies [16].

Iran has also been witnessing an era of urbanization over the past three decades. The most recent census in Iran showed that almost $74 \%$ of the Iranian population live in urban areas, i.e., just $25 \%$ of Iranians are residents of rural areas. Previous statistics of populations living in urban areas were 71 and $68 \%$, according to censuses conducted in 2011 and 2006, respectively, indicating that although Iran is experiencing a slow, but steady, increase in the urban population, a significant proportion of Iranians still resides in rural areas (https://nnt.sci.org.ir/ sites/nnt/SitePages/report_90/population_report.aspx).

Despite the expansion of urbanization and the alarming rate of hypertension in non-Western countries, less attention has been paid to comparing trends of hypertension and its comparison in urban and rural adolescents; for example, one study investigating urban-rural disparity in blood pressure among Chinese children between 1985 and 2010, showed higher blood pressure levels in rural children than their urban counterparts, which could not be explained by body mass index (BMI) status [17]. Data from Iran shows differences in mean systolic and diastolic blood pressure (SBP and DBP, respectively) between adults in urban and rural populations, in and around the city of Isfahan in central Iran [18]. However, there is no study comparing the trend of childhood pre-hypertension and hypertension between urban and rural residential areas of the country. Given this gap in evidence, the present study aimed to assess the trend of pre-hypertension and hypertension in pediatric populations of urban versus rural areas in Iran.

\section{Methods \\ Study population}

This study has been conducted within the framework of the national Surveillance of Risk Factors of Non-Communicable Diseases (SuRFNCD), using guidelines of the stepwise approach to NCD risk factor surveillance of the World Health Organization [19]. The SuRFNCD, which consists of several cross-sectional studies, was initiated in 2004 and repeated almost annually until 2011. Briefly, using a multistage random cluster sampling method, data for a nationally represented sample of urban and rural populations of all provinces of Iran has been assessed through each survey. Data were collected by trained nurses during household interviews. Details of the SuRFNCD have been published previously [20].

Adolescent boys and girls, aged 15-19 years, whose SBP and DBP were above the mean $\pm 3 \mathrm{SD}$, were considered as outliers and were excluded from the study; hence, those who participated in the $2007(n=2936)$, $2008(n=2988), 2009(n=2862)$, and $2011(n=929)$ surveys, entered the study. The surveys received ethical approval of the Center for Disease Control of Iran. Data recorded on age, sex, residential area, physical activity, BMI, SBP, and DBP were analyzed.

\section{Measurements}

After at least $10 \mathrm{~min}$ of resting in the sitting position two measurements of blood pressure (BP) were obtained within 5 minutes of each other, from the right arm of participants; by trained health-staff using an appropriate sized cuff [20]. Blood pressure was measured manually with a calibrated Omron M7 sphygmomanometer (HEM-780-E), and the mean of the two abovementioned measurements was considered as the participant's BP.

BMI was calculated as the weight in kilograms divided by the square of height in meters.

Physical activity was obtained using the global physical activity questionnaire (GPAQ), a standardized questionnaire developed by WHO, as a physical activity surveillance instrument. The translation of the second version of GPAQ was used for the assessment of physical activity [21]. Another questionnaire was used to collect demographic data, including occupation, sex, age, province, and area.

\section{Definition of terms}

For adolescents, aged 15-17 years, normal blood pressure was defined as systolic blood pressures (SBP) and diastolic blood pressures (DBP) <90th percentile, and pre-hypertension was defined as SBP or DBP $\geq 90$ th but 
$<$ 95th percentile, or BP levels $\geq 120 / 80 \mathrm{mmHg}$, considering the participant's age-sex-height. In addition, hypertension was defined as SBP and/or DBP $\geq 95$ th percentile. For adolescents, aged 18-19 years, pre-hypertension was defined as either SBP of $>120$ but $<140 \mathrm{mmHg}$ or DBP of $>80$ but $<90 \mathrm{mmHg}$; hypertension was defined as $\mathrm{SBP} \geq$ $140 \mathrm{mmHg}$ and DBP $\geq 90 \mathrm{mmHg}$, or taking antihypertensive medication [22] . Based on the GPAQ analysis framework, physical activity was defined at the three following levels: (1) High: vigorous-intensity activity, on at least 3 days a week, achieving a minimum of at least 1500 MET minutes per week, or 7 days of any combination of walking and moderate- or vigorous-intensity activities, achieving a minimum of at least 3000 MET-minutes per week; (2) Moderate: three or more days of vigorous-intensity activity of at least $20 \mathrm{~min}$ per day, or five or more days of moderate-intensity activity (including walking) of at least 30 min per day, or five or more days of any combination of walking, moderate- or vigorous intensity activities, achieving a minimum of at least 600 MET-minutes per week; and (3) Low: not meeting any of the abovementioned criteria [21].

\section{Statistical analysis}

Complex sample survey analysis was performed to obtain representative estimates of the Iranian population, in 2007, 2008, 2009, and 2011. Weights used for this analysis were generated for sex and area of residence (rural/urban), according to the population of Iran (national census, 2011).

Data from 2007 to 2011 SuRFNCD were pooled. Characteristics of participants were summarized as mean \pm standard error and frequencies (percentages), for continuous and categorical variables, respectively; the unadjusted and adjusted prevalence rates and their 95\% confidence intervals were estimated.

Sex-stratified prevalence rate of pre-hypertension and hypertension over SuRFNCD cycles across area of residence were computed by taking the predicted marginal from the logistic regression model. Differences in linear trends in the prevalence of pre-hypertension and hypertension over SuRFNCD cycles across the area of residence were examined by modeling interaction terms (e.g., area $\times$ SuRFNCD cycle) for boys and girls, separately.

Multinomial logistic was used to test for temporal trends of pre-hypertension and hypertension prevalence across the 5 SuRFNCD cycles. In models, blood pressure levels were considered as dependent categorical variable and time was included as a categorical variable as follows: 0 for 2007, 1 for 2008, 2 for 2009, and 4 for 2011. The time variable was used to assess temporal trends.
Adjusted prevalence ratios (PRs) for sex (girls as reference) were shown in two different models; model 1, adjusted for year $\left(1^{\mathrm{a}}\right)$, and model 2 further adjusted for physical activity and BMI $\left(2^{\mathrm{a}}\right)$. A similar approach was applied for calculating adjusted PRs for the residential area (urban as reference) (model $1^{\mathrm{b}}$ and $2^{\mathrm{b}}$, respectively). PRs and 95\% CIs were calculated for all models.

All analyses were performed using STATA version 14.0 , and $P$ values $<.05$ were considered statistically significant.

\section{Results}

A total of 9715 (5257 boys; 4458 girls) urban and rural adolescents, aged 15-19years, who participated in SuRFNCD between 2007 and 2011, were recruited in the current analysis.

Socio-demographic and anthropometric characteristics, based on the urban and rural areas, have been presented in Table 1. To provide more details of the study participants, a sex-specific table has also been considered as a supplementary document (Table 4 in Appendix).

The average SBP was changed from 119.41 to 119.76 and 110.37 to 112.24 in SuRFNCD 2007-2011 for boys and girls; corresponding values for DBP changed from 72.15 to 71.53 and 72.66 to 71.78 , respectively (Fig. 1). For more clarification, average SBP and DBP based on gender/area groups are illustrated in Figure 4 in Appendix. In addition, using the JNC-VII guideline and regardless of residential area, prevalence of both pre-hypertension and hypertension in SuRFNCD 20072011 for the whole population and separately for genders is illustrated in Fig. 2. Accordingly, the prevalence of pre-hypertension and hypertension changed from 25.34 and 10.25 in 2007 to 25.29 and $11.41 \%$ in 2011 among the whole population.

The prevalence of pre-hypertension and hypertension for different gender/area categories, based on the four national surveys mentioned, is illustrated in Fig. 3a and b. In both genders, the interactions of area and SuRFNCD cycles were not significant, either for pre-hypertension $(P$-interaction $=0.31$ and 0.59 for boys and girls, respectively) or hypertension status ( $P$-interaction $=0.13$ and 0.95 for boys and girls, respectively). In addition, unadjusted prevalence of pre-hypertension and hypertension is shown in Table 5 in Appendix of the manuscript.

The highest prevalence of pre-hypertension for boys (urban 31.61\% and rural 34.34\%) and girls (urban $20.06 \%$ and rural $24.13 \%$ ), was documented in 2009 and 2011, respectively. However, in both genders and areas, the highest prevalence of hypertension was observed in the last survey, conducted in 2011 (urban boys 15.04\% and rural boys 11.79\%; 
Table 1 Area-specific characteristics of adolescents, aged 15-19 years: SuRFNCD 2007-2011

\begin{tabular}{|c|c|c|c|c|c|c|c|c|}
\hline \multirow[t]{2}{*}{ Year } & \multicolumn{4}{|l|}{ Urban } & \multicolumn{4}{|l|}{ Rural } \\
\hline & $\begin{array}{l}2007 \\
(n=1718)\end{array}$ & $\begin{array}{l}2008 \\
(n=1819)\end{array}$ & $\begin{array}{l}2009 \\
(n=1550)\end{array}$ & $\begin{array}{l}2011 \\
(n=615)\end{array}$ & $\begin{array}{l}2007 \\
(n=1218)\end{array}$ & $\begin{array}{l}2008 \\
(n=1169)\end{array}$ & $\begin{array}{l}2009 \\
(n=1312)\end{array}$ & $\begin{array}{l}2011 \\
(n=314)\end{array}$ \\
\hline Age (years) & $17.60 \pm 0.03$ & $17.59 \pm 0.03$ & $17.59 \pm 0.04$ & $17.73 \pm 0.06$ & $17.55 \pm 0.04$ & $17.56 \pm 0.04$ & $17.61 \pm 0.04$ & $17.62 \pm 0.08$ \\
\hline \multicolumn{9}{|l|}{ Sex (\%) } \\
\hline Girls & $751(43.7)$ & $811(44.6)$ & $716(46.2)$ & $332(54)$ & $551(45.2)$ & $528(45.2)$ & $603(46)$ & $166(52.9)$ \\
\hline Boys & $967(56.3)$ & $1008(55.4)$ & $834(53.8)$ & $283(46)$ & $667(54.8)$ & $641(54.8)$ & $709(54)$ & $148(47.1)$ \\
\hline \multicolumn{9}{|c|}{ Physical activity (\% \pm SE) } \\
\hline High & $38.39 \pm 1.02$ & $33.50 \pm 0.99$ & $32.98 \pm 1.07$ & $33.35 \pm 1.76$ & $49.25 \pm 1.27$ & $48.99 \pm 1.27$ & $49.45 \pm 1.21$ & $36.96 \pm 2.49$ \\
\hline Moderate & $29.80 \pm 1.10$ & $25.27 \pm 1.01$ & $28.81 \pm 1.14$ & $22.63 \pm 1.66$ & $24.50 \pm 1.22$ & $19.99 \pm 1.16$ & $22.26 \pm 1.15$ & $21.84 \pm 2.30$ \\
\hline Low & $31.80 \pm 1.06$ & $41.21 \pm 1.06$ & $38.20 \pm 1.16$ & $44.01 \pm 1.80$ & $26.3 \pm 1.18$ & $31.01 \pm 1.25$ & $28.27 \pm 1.13$ & $41.18 \pm 2.50$ \\
\hline $\mathrm{BMI}\left(\mathrm{kg} / \mathrm{m}^{2}\right)$ & $21.73 \pm 0.08$ & $21.80 \pm 0.08$ & $21.80 \pm 0.09$ & $21.86 \pm 0.16$ & $21.18 \pm 0.08$ & $21.30 \pm 0.09$ & $21.41 \pm 0.09$ & $21.21 \pm 0.21$ \\
\hline $\mathrm{SBP}(\mathrm{mmHg})$ & $114.09 \pm 0.28$ & $112.83 \pm 0.28$ & $113.69 \pm 0.28$ & $115.56 \pm 0.48$ & $115.57 \pm 0.34$ & $115.03 \pm 0.35$ & $115.07 \pm 0.33$ & $116.73 \pm 0.63$ \\
\hline $\mathrm{DBP}(\mathrm{mmHg})$ & $72.77 \pm 0.22$ & $72.77 \pm 0.21$ & $73.58 \pm 0.22$ & $72.09 \pm 0.39$ & $71.59 \pm 0.26$ & $72.10 \pm 0.27$ & $71.79 \pm 0.25$ & $70.60 \pm 0.49$ \\
\hline
\end{tabular}

Age, physical activity, BMI, SBP, and DBP values are mean \pm SEM. Variables (except sex) are weighted according to sex

urban girls $9.06 \%$ and rural girls $11.60 \%$ ). The adjusted prevalence of pre-hypertension and hypertension showed a constant trend in both genders and residential areas. In urban areas, prevalence of pre-hypertension in adolescents changed from 28.96 to $29.24 \%$ and 18.33 to $20.06 \%$ in boys and girls, respectively; and in rural adolescents it rose from $31.58 \%$ to $32.05 \%$ and $22.25 \%$ to $24.13 \%$, in boys and girls, respectively. A slightly rising prevalence of hypertension was also observed in boys and girls of both regions, (urban 12.76 to $15.04 \%$ and 8.02 to $9.06 \%$; rural 9.95 to $11.79 \%$ and 10.35 to $11.60 \%$, for boys and girls, respectively) (Table 2).

The gender/area-specific PRs of pre-hypertension and hypertension are presented in Table 3. The year-adjusted PRs of pre-hypertension and hypertension for boys were higher than girls, in both residential areas $\left(\right.$ model $\left.1^{\mathrm{a}}\right)$. Similarly, after further adjustment for physical activity and BMI, the PRs of pre-hypertension (2.16, 95\% CI $1.68-2.79$ and 1.92 , 95\% CI $1.57-2.34-$ urban and rural, respectively) and hypertension (2.40, 95\% CI 1.65-3.51 and 1.82, 95\% CI 1.36-2.45-urban and rural, respectively) were higher in boys than girls (model $2^{\mathrm{a}}$ ). Comparing PRs of pre-hypertension and hypertension in urban boys and girls with their rural counterparts, the year-adjusted results showed higher PR of pre-hypertension for rural girls than their urban counterparts, and lower PR of hypertension in rural compared to urban boys (model $1^{\mathrm{b}}$ ). However, after further adjustment for physical activity and BMI, only the rural girls showed higher PR of pre-hypertension than their urban counterparts $(1.33,95 \%$ CI 1.011.75) (model $2^{\mathrm{b}}$ ).

As a sensitivity analysis, using the new American Heart Association (AHA) guideline (pre-hypertension 120/ $\leq 80$ to $129 / \leq 80 \mathrm{mmHg}$ and hypertension $\geq 130 / \geq 80 \mathrm{mmHg}$ )
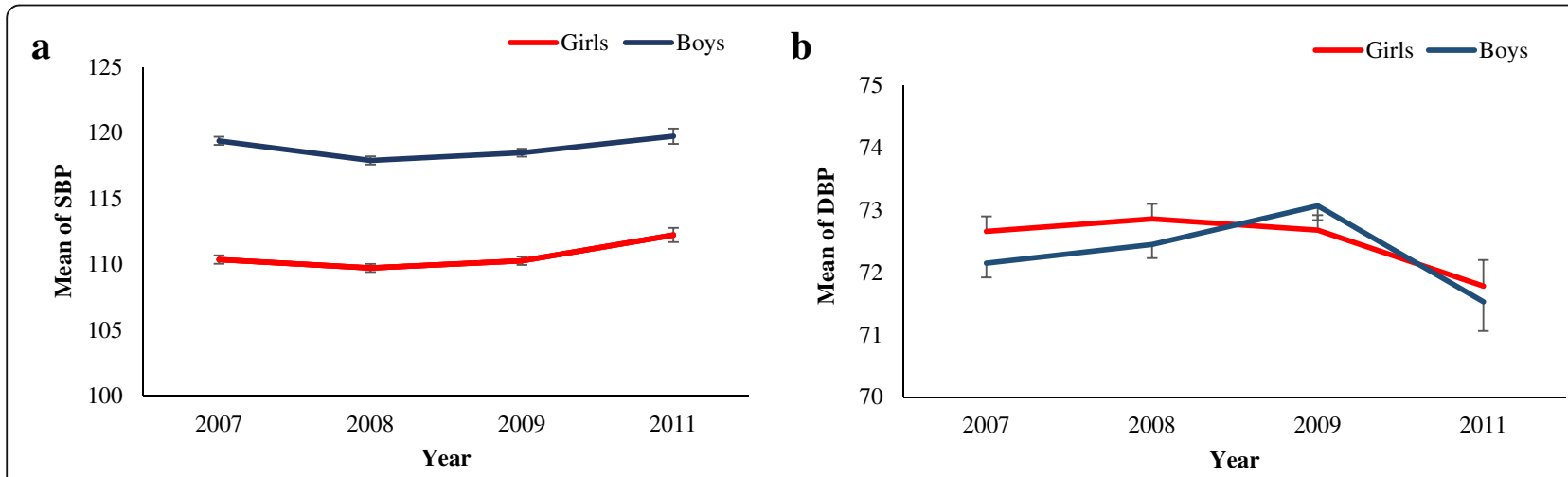

Fig. 1 a Gender-specific trend of systolic blood pressure (SBP) in adolescents aged 15-19years: SuRFNCD 2007-2011. b Gender-specific trend of diastolic blood pressure (DBP) in adolescents aged 15-19 years: SuRFNCD 2007-2011. Error bars show standard errors of mean 

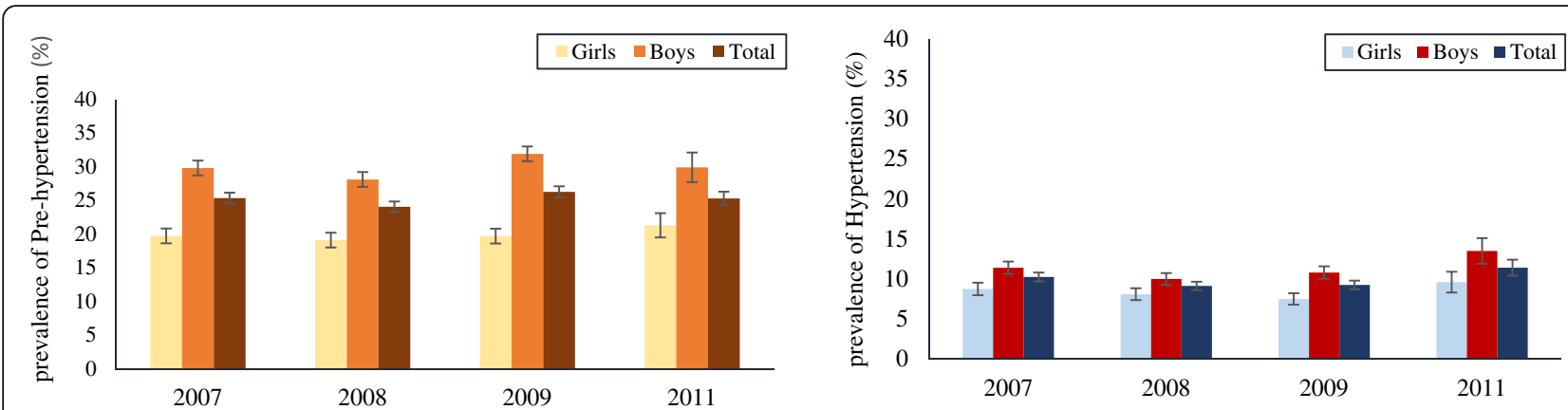

Fig. 2 Prevalence of pre-hypertension and hypertension based on JNC-VII guideline among girls, boys, and the total adolescent population in SURFNCD 2007-2011

[23] regardless of residential area, prevalence of both pre-hypertension and hypertension in SuRFNCD 20072011 for the whole population and in boys and girls separately is illustrated in Figure 5 in Appendix. Compared with the JNC-VII criteria, applying AHA cut points leads to a lower prevalence rate of pre-hypertension, but a significant increase in prevalence of hypertension in SuRFNCD 20072011. Using the AHA guideline, the prevalence of pre-hypertension and hypertension in the whole population changed from 14.23 to $29.18 \%$ and from 16.79 to $27.66 \%$ in the 2007 and 2011 surveys, respectively.

Moreover, the unadjusted prevalence and trend of pre-hypertension and hypertension using the new AHA guideline, based on residential area/sex groups, are shown in Table 6 and Figure 6 in Appendix.

\section{Discussion}

To the best of our knowledge, this is the first study in the MENA region and the third worldwide assessing the trend of high blood pressure among adolescents. The results of this study indicate a high constant prevalence of pre-hypertension and hypertension in boys and girls residing in both urban and rural areas, throughout the study period. For both areas, an overall higher prevalence of pre-hypertension and hypertension was observed in boys than girls; except for pre-hypertension that was significantly more prevalent in rural girls compared to their urban counterparts, the prevalence of pre-hypertension and hypertension was geographically independent.

The current findings regarding the considerable prevalence of pre-hypertension and hypertension, among Iranian adolescents, are consistent with some previous regional reports, indicating high blood pressure to be a nationwide problem among this age group in Iran [6, 7]. However, due to age variations, the comparison of the current results with other nationwide studies focused on Iranian school-aged children would be difficult $[24,25]$. Our results for all
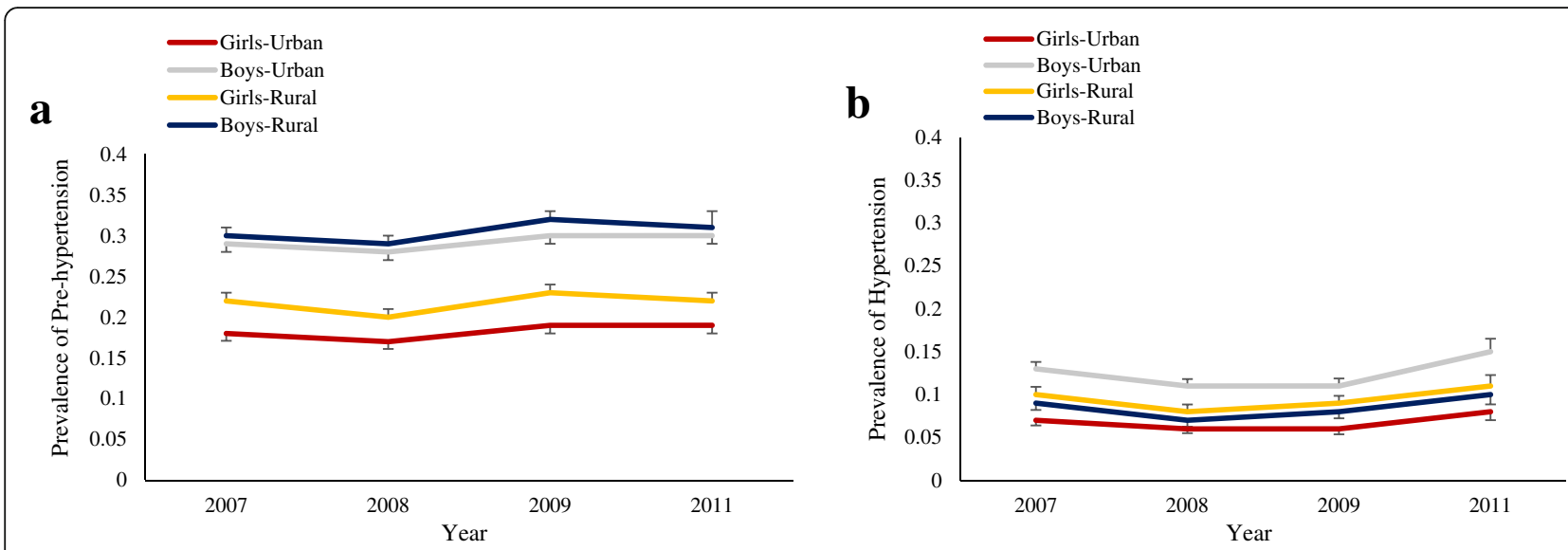

Fig. 3 a Gender/area-specific trend for unadjusted prevalence of pre-hypertension in Iranian adolescents, aged 15-19years based on JNC-VII guideline: SuRFNCD 2007-2011. P-interaction for girls-area $=0.59$ and for boys-area $=0.31$. b Gender/area-specific trend for unadjusted prevalence of hypertension in Iranian adolescents, aged 15-19years, based on JNC-VII guideline: SuRFNCD 2007-2011. P-interaction for girls-area $=0.95$ and for boys-area $=0.13$. Error bars show standard errors of marginal effects 
Table 2 Adjusted prevalence and trend of pre-hypertension and hypertension based on JNC-VII guideline in adolescents aged 1519: SuRFNCD 2007-2011

\begin{tabular}{|c|c|c|c|c|c|}
\hline Year & 2007 & 2008 & 2009 & 2011 & $P$ for trend \\
\hline \multicolumn{6}{|l|}{ Girls } \\
\hline \multicolumn{6}{|l|}{ Urban } \\
\hline Pre-hypertension & $18.33(15.91-20.75)$ & $17.71(15.36-20.06)$ & $18.04(15.55-20.52)$ & $20.06(16.41-23.71)$ & 0.540 \\
\hline Hypertension & $8.02(6.31-9.72)$ & $6.98(5.49-8.46)$ & $6.56(5.04-8.08)$ & $9.06(6.44-11.69)$ & 0.510 \\
\hline \multicolumn{6}{|l|}{ Rural } \\
\hline Pre-hypertension & $22.25(19.37-25.13)$ & $21.63(18.76-24.50)$ & $22.04(19.15-24.92)$ & $24.13(19.74-28.52)$ & 0.279 \\
\hline Hypertension & 10.35 (8.19-12.52) & $9.07(6.99-11.14)$ & $8.53(6.57-10.48)$ & $11.60(8.29-14.91)$ & 0.425 \\
\hline \multicolumn{6}{|l|}{ Boys } \\
\hline \multicolumn{6}{|l|}{ Urban } \\
\hline Pre-hypertension & $28.96(26.39-31.54)$ & $27.28(24.87-29.69)$ & $31.61(28.83-34.39)$ & $29.24(24.83-33.66)$ & 0.937 \\
\hline Hypertension & $12.76(10.82-14.71)$ & $10.81(9.12-12.50)$ & $12.27(10.26-14.28)$ & $15.04(11.26-18.82)$ & 0.099 \\
\hline \multicolumn{6}{|l|}{ Rural } \\
\hline Pre-hypertension & $31.58(28.36-34.80)$ & $26.65(26.59-32.71)$ & $34.34(31.10-37.58)$ & $32.05(27.03-37.07)$ & 0.182 \\
\hline Hypertension & $9.95(7.89-12.01)$ & $8.39(6.59-10.20)$ & $9.53(7.61-11.44)$ & 11.79 (8.69-14.89) & 0.502 \\
\hline
\end{tabular}

Prevalence rates were adjusted for physical activity and BMI

participants, regardless of gender and residential area, indicate the prevalence of pre-hypertension to be 24 and $25 \%$ for the first (2007) and the last (2011) examinations, respectively; the corresponding values for hypertension were 10 and 11\%, respectively (Fig. 2). More gender-specific results show a higher prevalence of pre-hypertension and hypertension in Iranian adolescent boys than girls. Comparing current results with existing evidence from other countries, data from NHANES in 2003-2006 [26] and 2011-
2013 [27] show the prevalence of elevated BP, including both pre-hypertension and hypertension, among US adolescents aged $13-17$ years, to be $2.6 \%$ and $1.3 \%$, respectively. In addition, data from China in 2004 indicate the prevalence of pre-hypertension and hypertension to be $9.5 \%$ and $21.0 \%$ among adolescents aged 13-17 years [28]. Another study (2010) revealed prevalence of $17-25 \%$ among $15-$ 17 -year-old Chinese adolescents suffering from hypertension [29].

Table 3 Prevalence ratios of pre-hypertension and hypertension based on JNC-VII guideline in adolescents aged 15-19years: SURFNCD 2007-2011

\begin{tabular}{|c|c|c|c|c|c|}
\hline & & Urban & & Rural & \\
\hline & & Pre-hypertension & Hypertension & Pre-hypertension & Hypertension \\
\hline \multirow[t]{2}{*}{ Model $1^{a}$} & Girls & Reference & Reference & Reference & Reference \\
\hline & Boys & $2.06(1.65-2.59)$ & $2.20(1.58-3.07)$ & $1.88(1.58-2.24)$ & $1.73(1.33-2.23)$ \\
\hline \multirow[t]{4}{*}{ Model $2^{a}$} & Girls & Reference & Reference & Reference & Reference \\
\hline & Boys & $2.16(1.68-2.79)$ & $2.40(1.65-3.51)$ & $1.92(1.57-2.34)$ & $1.82(1.36-2.45)$ \\
\hline & & Girls & & Boys & \\
\hline & & Pre-hypertension & Hypertension & Pre-hypertension & Hypertension \\
\hline \multirow[t]{2}{*}{ Model $1^{b}$} & Urban & Reference & Reference & Reference & Reference \\
\hline & Rural & $1.32(1.01-1.72)$ & $1.42(0.97-2.08)$ & $0.99(0.78-1.26)$ & $0.65(0.46-0.92)$ \\
\hline \multirow[t]{2}{*}{ Model $2^{b}$} & Urban & Reference & Reference & Reference & Reference \\
\hline & Rural & $1.33(1.01-1.75)$ & $1.41(0.96-2.09)$ & $1.08(0.85-1.38)$ & $0.77(0.53-1.11)$ \\
\hline
\end{tabular}

Model $1^{\text {a }}$ : adjusted model for year

Model $1^{\mathrm{b}}$ : adjusted model for year

Model $2^{a}$ : adjusted model for year, physical activity, and BMI

Model $2^{\mathrm{b}}$ : adjusted model for year, physical activity, and BMI

Reference: Normal group 
Factors affecting hypertension and prehypertension in pediatric populations are multiple. Data from NHANES [30], and another study in China [31], indicate that the major determinant of the recent increase in the prevalence of childhood hypertension is a concomitant increase in childhood obesity. However, adjustments for BMI in these studies suggested that other influencing factors are involved. In the current study, BMI adjusted trends of pre-hypertension and hypertension indicate a weight independent trend of elevated blood pressure in Iranian adolescents as well. According to protocol of the SuRFNCD, unfortunately, for participants aged < 25 years, no blood sampling has been performed [19], so information on fasting blood sugar and lipid profiles in this age group is not available for the current analysis. However, another national study conducted between 2009 and 2010 among 5940 Iranian adolescents, aged 10-18, reported the prevalence of $12.8 \%$ and $18.45 \%$ for high FBS among boys and girls, respectively; corresponding values for high TG (TG $\geq 130 \mathrm{mg} / \mathrm{dl}$ ) were $14.8 \%$ and $13.8 \%$, respectively [32]. This considerable prevalence of cardio-metabolic risk factors among Iranian children might be attributed to nutrition transition in Iran and the preference of Iranian families for Western eating patterns through the last decades [33] which could be independent of their weight status [34]. In this regard, more evidence shows $73.8 \%$ of Iranian school-aged children consumed hydrogenated solid fat, and about $80 \%$ of them add table salt to their food [25].

The current study shows similar constant trends of pre-hypertension and hypertension in both urban and rural Iranian adolescents, through 2007-2011. Previous data comparing high blood pressure and its main determinants among Iranian children, residing in urban and rural areas, are sparse. Looking through international data indicates that the urban/rural disparity for high blood pressure during early years of life is controversial and might vary between countries. While some studies revealed cardio-metabolic risk factors to be geographically independent $[35,36]$, other evidence suggest a significant difference in the prevalence of high blood pressure between urban and rural children [37, 38], without any specific explanation for the cause of this disparity [39].

The current similar trend of early high blood pressure in urban and rural areas of Iran could be explained by a major lifestyle transition, especially the increased dominance of Western food patterns among Iranian families over the last decades, resulting in 2 fold burden of nutritional disorders among Iranian children, particularly in rural areas [40].
Consistently, a recent nationwide study revealed that although Iranian children in rural areas were more physically active, they had less healthy dietary habits than their urban counterparts, especially in regions with a low socio-economic status (SES) [41], findings in agreement with those of several previous studies, which documented high physical activity [42-45], high consumption of traditional/salty meals [2, 46], and high prevalence of obesity among rural adolescents [46].

Although the current results indicate an overall higher probability of pre-hypertension and hypertension in boys than girls, rural girls compared to their counterparts in urban areas were at higher risk for pre-hypertension. Despite the lack of accurate behavioral assessments in the current study, data from another nationwide study in Iran indicated that, compared to boys, girls, in regions with different SES, were less physically active [41]; this gender difference in lifestyle habits could be explained by the different cultural conditions and social opportunities for boys and girls, which has also been reported by other studies in Iran [47] and a majority of other Muslim communities as well $[48,49]$.

As for strengths, this is the first nationwide gender/ area-specific report on the trend of pre-hypertension and hypertension among Iranian adolescents, preformed over four repeated cross-sectional surveys. Regarding limitations, data on dietary status of the participants was not available; hence, we could not consider this important confounder in data analysis. In addition, following widespread migration from rural to urban areas in Iran, during the recent decades, we were unable to consider marginalization and its influence on lifestyle patterns and diseases in this study. Thus, future research should include sub-urban children, as a third comparison group, considering their behavioral, cultural, and environmental characteristics, which could affect their blood pressure status.

\section{Conclusions}

Overall, the current results show constant high trends of pre-hypertension and hypertension in Iranian boys and girls, residing in both urban and rural areas. Moreover, boys were more likely to be affected for both pre-hypertension and hypertension than girls, and rural girls showed higher prevalence ratio of pre-hypertension than their urban counterparts. Future research targeted at genetic, behavioral, and socio-environmental determinants underlying and influencing these constant high trends of elevated blood pressure among adolescent should be considered in both urban and rural areas of the country. 


\section{Appendix}
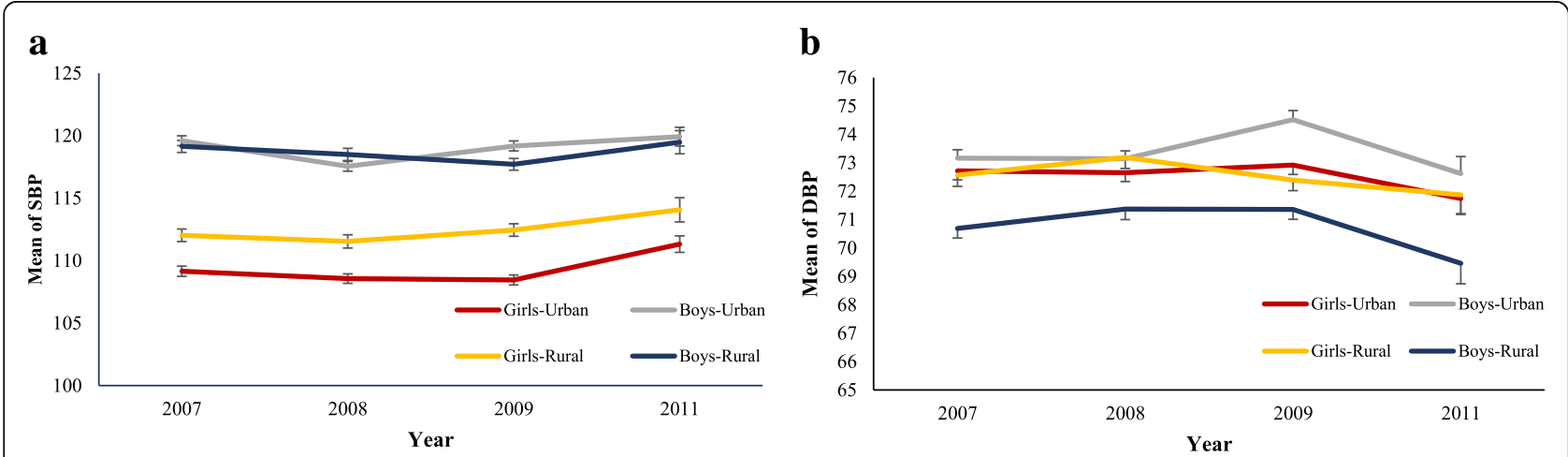

Fig. 4 a Gender/area-specific trend of systolic blood pressure (SBP) in adolescents aged 15-19years: SuRFNCD 2007-2011. b Gender/area-specific trend of diastolic blood pressure (DBP) in adolescents aged 15-19 years: SuRFNCD 2007-2011. Error bars show standard errors of mean
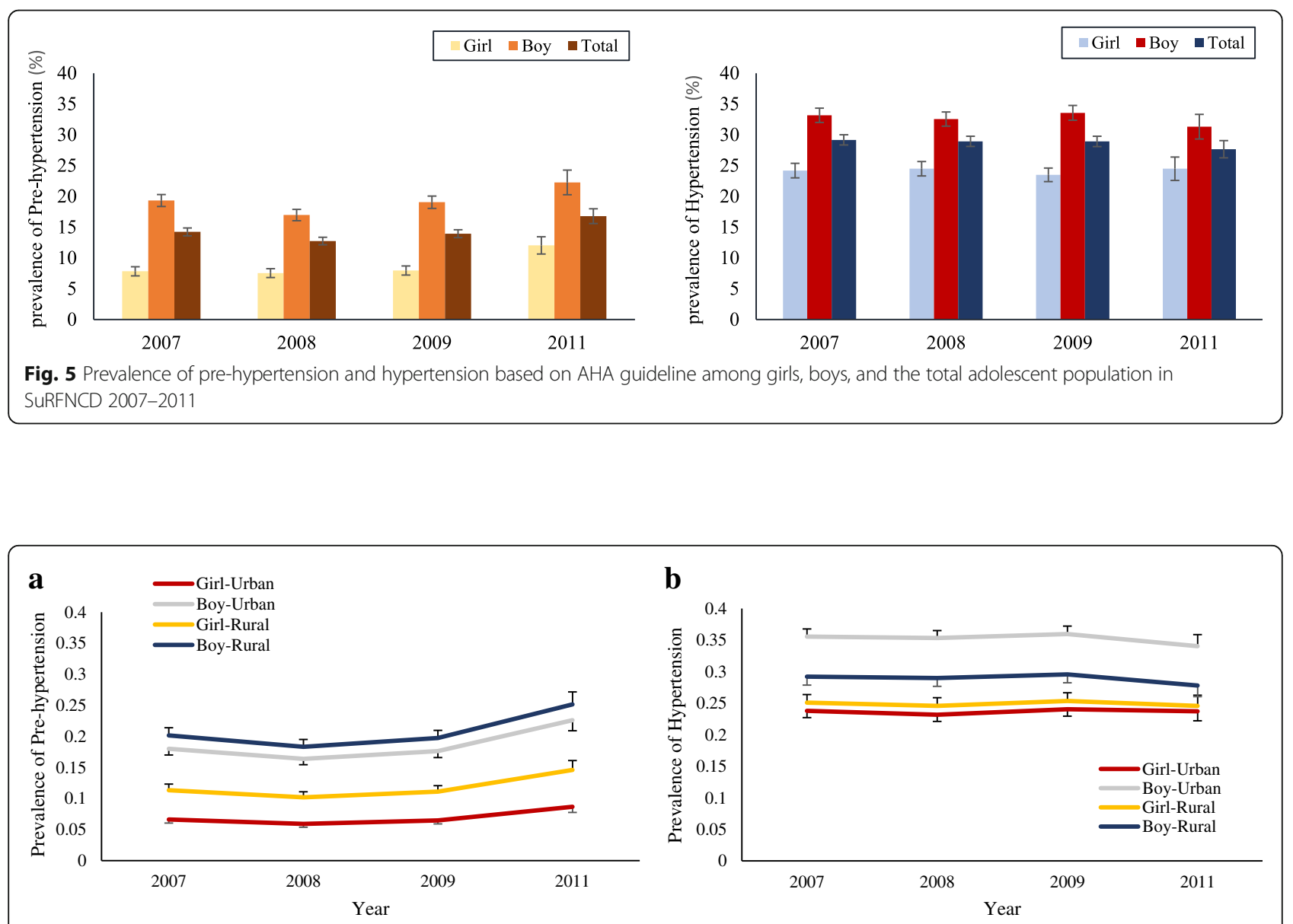

Fig. 6 a Gender/area-specific trend for unadjusted prevalence of pre-hypertension in Iranian adolescents, aged 15-19years based on AHA guideline: SuRFNCD 2007-2011. P-interaction for girls/area $=0.39$ and for boys/area $=0.26$. b Gender/area-specific trend for unadjusted prevalence of hypertension in Iranian adolescents, aged 15-19years, based on AHA guideline: SuRFNCD 2007-2011. P-interaction for girls-area $=0.99$ and for boys-area $=0.49$. Error bars show standard errors of marginal effects 
Table 4 Sex-specific characteristics of adolescents, aged 15-19years: SuRFNCD 2007-2011

\begin{tabular}{|c|c|c|c|c|c|c|c|c|}
\hline \multirow[t]{2}{*}{ Year } & \multicolumn{4}{|l|}{ Girls } & \multicolumn{4}{|l|}{ Boys } \\
\hline & $\begin{array}{l}2007 \\
(n=1302)\end{array}$ & $\begin{array}{l}2008 \\
(n=1339)\end{array}$ & $\begin{array}{l}2009 \\
(n=1319)\end{array}$ & $\begin{array}{l}2011 \\
(n=498)\end{array}$ & $\begin{array}{l}2007 \\
(n=1634)\end{array}$ & $\begin{array}{l}2008 \\
(n=1649)\end{array}$ & $\begin{array}{l}2009 \\
(n=1543)\end{array}$ & $\begin{array}{l}2011 \\
(n=431)\end{array}$ \\
\hline Age (years) & $17.67 \pm 0.03$ & $17.69 \pm 0.03$ & $17.57 \pm 0.04$ & $17.69 \pm 0.06$ & $17.50 \pm 0.03$ & $17.46 \pm 0.03$ & $17.61 \pm 0.03$ & $17.70 \pm 0.07$ \\
\hline \multicolumn{9}{|c|}{ Residential area (\%) } \\
\hline Urban & $751(57.7)$ & $811(60.6)$ & $716(54.3)$ & $332(66.7)$ & $967(59.2)$ & $1008(61.1)$ & $834(54.1)$ & $283(65.7)$ \\
\hline Rural & $551(42.3)$ & $528(39.4)$ & $603(45.7)$ & $166(33.3)$ & $667(40.8)$ & $641(38.9)$ & $709(45.9)$ & $148(34.3)$ \\
\hline \multicolumn{9}{|c|}{ Physical activity (\% \pm SE) } \\
\hline High & $19.66 \pm 1.08$ & $19.21 \pm 1.05$ & $18.37 \pm 1.05$ & $16.07 \pm 1.63$ & $63.56 \pm 1.19$ & $57.29 \pm 1.16$ & $57.70 \pm 1.27$ & $52.50 \pm 2.36$ \\
\hline Moderate & $35.68 \pm 1.35$ & $27.97 \pm 1.22$ & $30.91 \pm 1.31$ & $23.90 \pm 1.83$ & $20.70 \pm 1.02$ & $19.28 \pm 0.97$ & $22.60 \pm 1.10$ & $20.90 \pm 1.98$ \\
\hline Low & $44.65 \pm 1.37$ & $52.80 \pm 1.34$ & $50.71 \pm 1.39$ & $60.01 \pm 2.09$ & $15.73 \pm 0.90$ & $23.42 \pm 0.98$ & $19.68 \pm 1.04$ & $26.58 \pm 2.05$ \\
\hline $\mathrm{BMI}\left(\mathrm{kg} / \mathrm{m}^{2}\right)$ & $21.78 \pm 0.09$ & $21.92 \pm 0.10$ & $21.94 \pm 0.11$ & $22.03 \pm 0.18$ & $21.33 \pm 0.08$ & $21.37 \pm 0.08$ & $21.40 \pm 0.09$ & $21.27 \pm 0.17$ \\
\hline $\mathrm{SBP}(\mathrm{mmHg})$ & $109.89 \pm 0.31$ & $109.35 \pm 0.31$ & $109.63 \pm 0.31$ & $112.21 \pm 0.52$ & $119.21 \pm 0.30$ & $117.63 \pm 0.30$ & $118.63 \pm 0.30$ & $119.61 \pm 0.56$ \\
\hline $\mathrm{DBP}(\mathrm{mmHg})$ & $72.58 \pm 0.25$ & $72.71 \pm 0.24$ & $72.71 \pm 0.25$ & $71.74 \pm 0.41$ & $72.20 \pm 0.23$ & $72.40 \pm 0.22$ & $73.29 \pm 0.24$ & $71.49 \pm 0.45$ \\
\hline
\end{tabular}

Age, physical activity, BMI, SBP, and DBP values are mean \pm SEM

Variables (except residential area) are weighted according to residential area

Table 5 Unadjusted prevalence and trend of pre-hypertension and hypertension based on JNC-VII in Iranian adolescents: SuRFNCD 2007-2011

\begin{tabular}{|c|c|c|c|c|c|}
\hline Year & 2007 & 2008 & 2009 & 2011 & $P$ for trend \\
\hline \multicolumn{6}{|l|}{ Girls } \\
\hline \multicolumn{6}{|l|}{ Urban } \\
\hline Pre-hypertension & 18.18 (15.90-20.47) & 17.66 (15.44-19.89) & $18.04(15.72-20.36)$ & $19.92(16.42-23.42)$ & 0.624 \\
\hline Hypertension & $7.86(6.23-9.49)$ & $7.04(5.63-8.46)$ & $6.56(5.08-8.04)$ & $8.78(6.30-11.27)$ & 0.500 \\
\hline \multicolumn{6}{|l|}{ Rural } \\
\hline Pre-hypertension & 21.99 (19.14-24.85) & 21.47 (18.64-24.29) & $21.93(19.11-24.76)$ & 23.89 (19.59-28.18) & 0.322 \\
\hline Hypertension & $10.27(8.14-12.39)$ & $9.24(7.20-11.28)$ & $8.62(6.68-10.55)$ & 11.37 (8.22-14.53) & 0.595 \\
\hline \multicolumn{6}{|l|}{ Boys } \\
\hline \multicolumn{6}{|l|}{ Urban } \\
\hline Pre-hypertension & $29.40(26.89-31.90)$ & 27.57 (25.18-29.97) & $32.26(29.53-34.99)$ & $29.20(24.79-33.60)$ & 0.936 \\
\hline Hypertension & $12.94(11.08-14.79)$ & $11.25(9.53-12.97)$ & $12.38(10.43-14.34)$ & $15.18(11.47-18.89)$ & 0.108 \\
\hline \multicolumn{6}{|l|}{ Rural } \\
\hline Pre-hypertension & $30.75(27.78-33.71)$ & $28.66(25.77-31.56)$ & $33.67(20.62-36.72)$ & $30.78(25.91-35.66)$ & 0.244 \\
\hline Hypertension & $8.87(7.13-10.62)$ & 7.67 (6.08-9.26) & $8.48(6.77-10.18)$ & $10.50(7.80-13.19)$ & 0.390 \\
\hline
\end{tabular}


Table 6 Unadjusted prevalence and trend of pre-hypertension and hypertension based on AHA guideline in Iranian adolescents: SuRFNCD 2007-2011

\begin{tabular}{|c|c|c|c|c|c|}
\hline Year & 2007 & 2008 & 2009 & 2011 & $P$ for trend \\
\hline \multicolumn{6}{|l|}{ Girls } \\
\hline \multicolumn{6}{|l|}{ Urban } \\
\hline Pre-hypertension & $6.10(4.72-7.48)$ & $5.97(4.64-7.29)$ & $5.80(4.52-7.09)$ & $9.82(7.31-12.32)$ & 0.18 \\
\hline Hypertension & $23.59(21.04-26.15)$ & 23.86 (21.34-26.38) & $22.95(20.39-25.50)$ & $24.28(20.42-28.15)$ & 0.61 \\
\hline \multicolumn{6}{|l|}{ Rural } \\
\hline Pre-hypertension & $10.51(8.32-12.71)$ & $10.29(8.16-12.42)$ & $10.04(7.90-12.17)$ & $16.42(12.22-20.61)$ & 0.06 \\
\hline Hypertension & $24.98(22.04-27.92)$ & $25.27(22.28-28.27)$ & $24.37(21.50-27.25)$ & $24.93(20.72-29.14)$ & 0.69 \\
\hline \multicolumn{6}{|l|}{ Boys } \\
\hline \multicolumn{6}{|l|}{ Urban } \\
\hline Pre-hypertension & $18.59(16.46-20.73)$ & $16.32(14.34-18.31)$ & 18.35 (16.11-20.60) & $21.33(17.48-25.17)$ & 0.66 \\
\hline Hypertension & $35.71(33.08-38.34)$ & 34.61 (32.07-37.16) & $37.01(34.20-39.82)$ & $33.51(28.96-38.07)$ & 0.78 \\
\hline \multicolumn{6}{|l|}{ Rural } \\
\hline Pre-hypertension & $20.80(18.18-23.42)$ & $18.21(15.76-20.67)$ & $20.60(17.97-23.23)$ & $23.70(19.22-28.17)$ & 0.12 \\
\hline Hypertension & $29.32(26.49-32.15)$ & $28.35(25.55-31.16)$ & $30.50(27.63-33.38)$ & $27.34(23.11-31.56)$ & 0.51 \\
\hline
\end{tabular}

\section{Abbreviations}

BMI: Body mass index; BP: Blood pressure; CVDs: Cardiovascular diseases; DBP: Diastolic blood pressure; EMR: Eastern Mediterranean region; GPAQ: Global physical activity questionnaire; PRs: Prevalence ratios; SBP: Systolic blood pressure; SES: Socio-economic status

\section{Acknowledgements}

We would like to express our appreciation to the participants of the national surveillance of risk factors of non-communicable diseases. The authors also wish to acknowledge Ms. Niloofar Shiva, Endocrine Research Center, for critical editing of English grammar and syntax of the manuscript.

\section{Funding}

This study was supported by the Center for Disease Control, Ministry of Health and Medical education, Tehran, Iran.

\section{Availability of data and materials}

The de-identified and anonymized information is potentially available on reasonable request.

\section{Authors' contributions}

PA and GV-N conceptualized and designed the study, drafted the initial manuscript, and reviewed and revised the manuscript. PN carried out the statistical analysis, drafted the initial manuscript, and reviewed and revised the manuscript. DK, SSHN, and YM designed, coordinated, and supervised the statistical analysis and reviewed and revised the manuscript. FA and ARMH reviewed and revised the manuscript. FH conceptualized and designed the study, coordinated and critically reviewed the manuscript for important intellectual content. All authors approved the final manuscript as submitted and agree to be accountable for all aspects of the work.

\section{Ethics approval and consent to participate}

The surveys received ethical approval of the Center for Disease Control of Iran. Verbal consent was provided by participants for this study.

\section{Consent for publication}

Not applicable.

\section{Competing interests}

The authors declare that they have no competing interests.

\section{Publisher's Note}

Springer Nature remains neutral with regard to jurisdictional claims in published maps and institutional affiliations.

\section{Author details}

${ }^{1}$ Research Center for Social Determinants of Health, Research Institute for Endocrine Sciences, Shahid Beheshti University of Medical Sciences, Tehran, Iran. ${ }^{2}$ Department of Biostatistics, School of Paramedical Sciences, Shahid Beheshti University of Medical Sciences, Tehran, Iran. ${ }^{3}$ Prevention of Metabolic Disorders Research Center, Research Institute for Endocrine Sciences, Shahid Beheshti University of Medical Sciences, Tehran, Iran. ${ }^{4}$ Safety Promotion and Injury Prevention Research Center, Department of Epidemiology, School of Public Health and Safety, Shahid Beheshti University of Medical Sciences, Tehran, Iran. ${ }^{5}$ Department of Epidemiology, School of Public Health, Shahid Beheshti University of Medical Sciences, Tehran, Iran. ${ }^{6}$ Center for Non-communicable Diseases Control, Ministry of Health and Medical Education, Tehran, Iran. ${ }^{7}$ Endocrine Research Center, Research Institute for Endocrine Sciences, Shahid Beheshti University of Medical Sciences, Tehran, Iran.

Received: 16 October 2018 Accepted: 18 March 2019

Published online: 29 March 2019

\section{References}

1. Organization WH, Unit WHOMoSA. Global status report on alcohol and health, 2014. Geneva: WHO Press; 2014.

2. Fahed AC, El-Hage-Sleiman A-KM, Farhat TI, Nemer GM. Diet, genetics, and disease: a focus on the Middle East and North Africa region. J Nutr Metab. 2012;2012:1-19.

3. Turk-Adawi K, Sarrafzadegan N, Fadhil I, Taubert K, Sadeghi M, Wenger NK, et al. Cardiovascular disease in the Eastern Mediterranean region: epidemiology and risk factor burden. Nat Rev Cardiol. 2017;15(2):106-19.

4. Malekzadeh MM, Etemadi A, Kamangar F, Khademi H, Golozar A, Islami F, et al. Prevalence, awareness and risk factors of hypertension in a large cohort of Iranian adult population. J Hypertens. 2013;31(7):1364.

5. Howe LD, Chaturvedi N, Lawlor DA, Ferreira DL, Fraser A, Smith GD, et al. Rapid increases in infant adiposity and overweight/obesity in childhood are associated with higher central and brachial blood pressure in early adulthood. J Hypertens. 2014;32(9):1789.

6. Akbari M, Moosazadeh M, Ghahramani S, Tabrizi R, Kolahdooz F, Asemi Z, et al. High prevalence of hypertension among Iranian children and adolescents: a systematic review and meta-analysis. J Hypertens. 2017;35(6): 1155-63. 
7. Fallah Z, Djalalinia S, Qorbani M, Farzadfar F, Kelishadi R. A systematic review of studies on blood pressure in Iranian pediatric population: first report from the Middle East and North Africa. Iran J Pediatr. 2016;26(2):e4496.

8. Ogden CL, Carroll MD, Kit BK, Flegal KM. Prevalence of obesity and trends in body mass index among US children and adolescents, 1999-2010. JAMA. 2012;307(5):483-90.

9. Rahmani A, Sayehmiri K, Asadollahi K, Sarokhani D, Islami F, Sarokhani M. Investigation of the prevalence of obesity in Iran: a systematic review and meta-analysis study. Acta Med Iran. 2015;53(10):596-607.

10. Harpham T. Urbanization and mental health in developing countries: a research role for social scientists, public health professionals and social psychiatrists. Soc Sci Med. 1994;39(2):233-45.

11. Riha J, Karabarinde A, Ssenyomo G, Allender S, Asiki G, Kamali A, et al. Urbanicity and lifestyle risk factors for cardiometabolic diseases in rural Uganda: a cross-sectional study. PLoS Med. 2014;11(7):e1001683.

12. Lindroth $M$, Lundqvist $R$, Lilja $M$, Eliasson M. Cardiovascular risk factors differ between rural and urban Sweden: the 2009 Northern Sweden MONICA cohort. BMC Public Health. 2014;14:825.

13. Donatiello E, Russo MD, Formisano A, Lauria F, Nappo A, Reineke A, et al. Physical activity, adiposity and urbanization level in children: results for the Italian cohort of the IDEFICS study. Public Health. 2013;127(8):761-5.

14. Carson V, lannotti RJ, Pickett W, Janssen I. Urban and rural differences in sedentary behavior among American and Canadian youth. Health Place. 2011;17(4):920-8.

15. Regis MF, Oliveira LMFT, Santos ARM, Leonidio ACR, Diniz PRB, Freitas CMSM. Urban versus rural lifestyle in adolescents: associations between environment, physical activity levels and sedentary behavior. Einstein (São Paulo). 2016;14(4):461-7.

16. Singh AP, Misra G. Adolescent lifestyle in India: prevalence of risk and promotive factors of health. Psychol Dev Soc. 2012;24(2):145-60.

17. Dong B, Wang Z, Ma J. Urban-rural disparity in blood pressure among Chinese children: 1985-2010. Eur J Public Health. 2015;26(4):569-75

18. SarrafZadegan N, AminiNik S. Blood pressure pattern in urban and rural areas in Isfahan. Iran J Hum Hypertens. 1997;11(7):425-8.

19. Asgari F, Mirzazadeh $A$, Heidarian $\mathrm{H}$. Iran non-communicable diseases risk factors surveillance data book National NCD Risk Factors Surveillance Committee; 2007.

20. Esteghamati A, Etemad K, Koohpayehzadeh J, Abbasi M, Meysamie A,

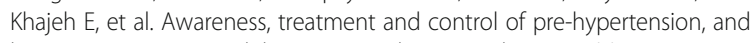
hypertension among adults in Iran. Arch Iran Med. 2016;19(7):456-64.

21. Esteghamati A, Khalilzadeh O, Rashidi A, Kamgar M, Meysamie A, Abbasi M. Physical activity in Iran: results of the third national surveillance of risk factors of non-communicable diseases (SuRFNCD-2007). J Phys Act Health. 2011;8(1):27-35.

22. Falkner B, Daniels SR, Flynn JT, Gidding S, Green LA, Ingelfinger JR, et al. The fourth report on the diagnosis, evaluation, and treatment of high blood pressure in children and adolescents. Pediatrics. 2004;114(2 III):555-76.

23. Flynn JT, Kaelber DC, Baker-Smith CM, Blowey D, Carroll AE, Daniels SR, et al. Clinical practice guideline for screening and management of high blood pressure in children and adolescents. Pediatrics. 2017;140(3):e20171904.

24. Fallah Z, Qorbani M, Motlagh ME, Heshmat R, Ardalan G, Kelishadi R. Prevalence of prehypertension and hypertension in a nationally representative sample of Iranian children and adolescents: the CASPIAN-IV study. Int J Prev Med. 2014;5(Suppl 1):S57.

25. Kelishadi R, Ardalan G, Gheiratmand R, Majdzadeh R, Delavari A, Heshmat R, et al. Blood pressure and its influencing factors in a national representative sample of Iranian children and adolescents: the CASPIAN study. Eur J Cardiovasc Prev Rehabil. 2006;13(6):956-63.

26. Ostchega Y, Carroll M, Prineas R, McDowell MA, Louis T, Tilert T. Trends of elevated blood pressure among children and adolescents: data from the National Health and Nutrition Examination Survey 1988-2006. Am J Hypertens. 2009;22(1):59-67.

27. Kit BK, Kuklina E, Carroll MD, Ostchega Y, Freedman DS, Ogden CL. Prevalence of and trends in dyslipidemia and blood pressure among US children and adolescents, 1999-2012. JAMA Pediatr. 2015;169(3):272-9.

28. Liang Y-J, Xi B, Hu Y-H, Wang C, Liu J-T, Yan Y-K, et al. Trends in blood pressure and hypertension among Chinese children and adolescents: China Health and Nutrition Surveys 1991-2004. Blood Press. 2011;20(1):45-53.

29. Dong Y, Ma J, Song Y, Dong B, Wang Z, Yang Z, et al. National blood pressure reference for Chinese Han children and adolescents aged 7 to 17 Years. Hypertension. 2017. https://doi.org/10.1161/HYPERTENSIONAHA.117.09983.
30. Rosner B, Cook NR, Daniels S, Falkner B. Childhood blood pressure trends and risk factors for high blood pressure: the NHANES experience 1988-2008. Hypertension. 2013;62(2):247-54.

31. Dong B, Wang HJ, Wang Z, Liu JS, Ma J. Trends in blood pressure and body mass index among Chinese children and adolescents from 2005 to 2010. Am J Hypertens. 2013;26(8):997-1004.

32. Kelishadi R, Heshmat R, Farzadfar F, Motlag ME, Bahreynian M, Safiri S, et al. Prevalence of cardio-metabolic risk factors in a nationally representative sample of Iranian adolescents: the CASPIAN-III study. J Cardiovasc Thorac Res. 2017;9(1):12.

33. Payab M, Kelishadi R, Qorbani M, Motlagh ME, Ranjbar SH, Ardalan G, et al. Association of junk food consumption with high blood pressure and obesity in Iranian children and adolescents: the CASPIAN-IV study. J Pediatr. 2015;91(2):196-205.

34. Azizi-Soleiman F, Motlagh ME, Qorbani M, Heshmat R, Ardalan G, Mansourian M, et al. Dietary habits and health related behaviors in Iranian children and adolescents: the CASPIAN-IV study. Int J Pediatr. 2016;4(7): 2087-97.

35. Ochoa-Avilés A, Andrade S, Huynh T, Verstraeten R, Lachat C, Rojas R, et al. Prevalence and socioeconomic differences of risk factors of cardiovascular disease in Ecuadorian adolescents. Pediatr Obes. 2012;7(4):274-83.

36. Mbowe O, Diaz A, Wallace J, Mazariegos M, Jolly P. Prevalence of metabolic syndrome and associated cardiovascular risk factors in Guatemalan school children. Matern Child Health J. 2014;18(7):1619-27.

37. Yamamoto-Kimura L, Posadas-Romero C, Posadas-Sánchez R, ZamoraGonzález J, Cardoso-Saldaña G, Ramírez IM. Prevalence and interrelations of cardiovascular risk factors in urban and rural Mexican adolescents. J Adolesc Health. 2006;38(5):591-8.

38. Su Z, Cheng H, Zhao D, Duan J, Wang L, Hou D, et al. Dietary habits of school-age children and its associations with blood pressure level in Beijing, China. Zhonghua Yu Fang Yi Xue Za Zhi. 2014;48(5):340-4.

39. Johnson lii JA, Johnson AM. Urban-rural differences in childhood and adolescent obesity in the United States: a systematic review and metaanalysis. Child Obes. 2015;11(3):233-41.

40. Rahmanian M, Kelishadi R, Qorbani M, Motlagh ME, Shafiee G, Aminaee T, et al. Dual burden of body weight among Iranian children and adolescents in 2003 and 2010: the CASPIAN-III study. Arch Med Sci. 2014;10(1):96.

41. Kelishadi R, Qorbani M, Motlagh ME, Ardalan G, Heshmat R, Hovsepian S. Socioeconomic disparities in dietary and physical activity habits of Iranian children and adolescents: the Caspian-IV study; 2016.

42. Liu J-H, Jones SJ, Sun H, Probst JC, Merchant AT, Cavicchia P. Diet, physical activity, and sedentary behaviors as risk factors for childhood obesity: an urban and rural comparison. Child Obes. 2012:8(5):440-8.

43. Lutfiyya MN, Lipsky MS, Wisdom-Behounek J, Inpanbutr-Martinkus M. Is rural residency a risk factor for overweight and obesity for US children? Obesity. 2007;15(9):2348-56.

44. Joens-Matre RR, Welk GJ, Calabro MA, Russell DW, Nicklay E, Hensley LD. Rural-urban differences in physical activity, physical fitness, and overweight prevalence of children. J Rural Health. 2008;24(1):49-54.

45. Davis A, Boles R, James R, Sullivan D, Donnelly J, Swirczynski D, et al. Health behaviors and weight status among urban and rural children. Rural Remote Health. 2008:8(2):810.

46. Wang Y, Monteiro C, Popkin BM. Trends of obesity and underweight in older children and adolescents in the United States, Brazil, China, and Russia. Am J Clin Nutr. 2002;75(6):971-7.

47. Amiri P, Ghofranipour F, Ahmadi F, Hosseinpanah F, Montazeri A, JalaliFarahani $S$, et al. Barriers to a healthy lifestyle among obese adolescents: a qualitative study from Iran. Int J Public Health. 2011;56(2):181-9.

48. Allafi A, Al-Haifi AR, Al-Fayez MA, Al-Athari Bl, Al-Ajmi FA, Al-Hazzaa HM, et al. Physical activity, sedentary behaviours and dietary habits among Kuwaiti adolescents: gender differences. Public Health Nutr. 2014;17(9):2045-52.

49. Al-Hazzaa HM, Abahussain NA, Al-Sobayel HI, Qahwaji DM, Musaiger AO Physical activity, sedentary behaviors and dietary habits among Saudi adolescents relative to age, gender and region. Int J Behav Nutr Phys Act. 2011:8(1):140 